\title{
Los libros sobre la Guerra Civil
}

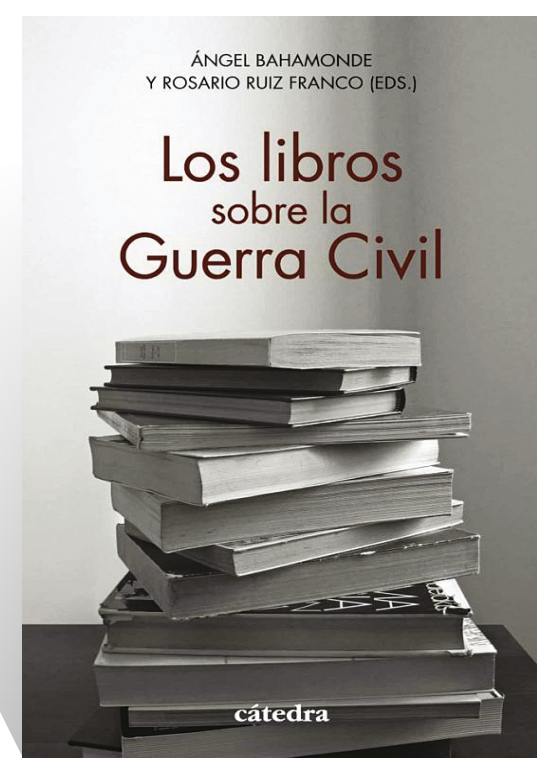

FICHA BIBLIOGRÁFICA

Ángel Bahamonde y Rosario Ruíz Franco (EDs.), Los libros sobre la Guerra Civil. Madrid, Cátedra, 2021, 2ª ed., páginas 296, ISBN: 978-84-376-4248-2.

Juan Andrés Blanco I Universidad de Salamanca

Decía el malogrado Pere Anguera que sobre temas tan tratados como la Guerra Civil Española de 1936 eran casi imprescindibles los análisis bibliográficos por la dificultad para el mismo historiador de orientarse adecuadamente en la profusión de títulos a la que había dado lugar. Y creo que tenía mucha razón. La Guerra Civil Española ha sido el proceso al que más atención han prestado la historiografía y la opinión pública extranjeras, al entenderlo como una especie de precedente o primera etapa del conflicto que se dirime en la Segunda Guerra Mundial. Y también desde España, pues se ha entendido ampliamente como un corte profundo, violento y duradero en la evolución histórica española. Por otro lado, asistimos a un constante uso político e ideológico de la historia desde el presente y con demasiada frecuencia se mezclan historiografía y mera propaganda junto a una creciente banalización de 
la investigación histórica. Y esto ocurre respecto a la Guerra Civil. De ahí la importancia de obras como la que aquí comentamos.

La profusa historiografía generada desde el mismo momento del inicio de la guerra no contó durante tiempo con adecuados análisis orientativos. Pero desde los años noventa vieron la luz varios y con ocasión del ochenta aniversario se han publicado algunos que considero valiosos. En la $7^{\circ}$ de las Bibliografías de Historia de España que publicó el CINDOC en 1996, en la que participó María del Rosario Ruiz Franco, se daba cuenta de los análisis de este tipo que se habían realizado hasta el momento y el autor de este comentario firmaba un estudio de la historiografía sobre la guerra publicada de 1975 a 1995. Este análisis fue completado posteriormente con otros estudios sobre esta temática con ocasión del sesenta y el setenta aniversarios.

En 2015 el profesor Ángel Viñas, sin duda uno de los historiadores que más ha aportado en las dos últimas décadas al conocimiento historiográfico de esta guerra, dirigió un número monográfico de la revista Studia Historica. Contemporánea que recogía 33 aportaciones de autores españoles y extranjeros sobre lo publicado en distintos campos entre 2006 y 2013 , periodo en el que predominaba ya claramente la aportación de historiadores españoles. Esta obra fue continuada y ampliada en un libro electrónico baja lo coordinación de Viñas y el autor de este comentario aportando la valoración de algunos otros especialistas ${ }^{1}$. En ese ciclo de estudios de la historiografía de la guerra se inscribe la obra que comentamos.

Lo primero a señalar es que estamos ante una obra de gran utilidad, pues ofrece a los lectores una orientación valorativa que completa los análisis mencionados y, publicada casi al mismo tiempo, se ve complementada por otra algo distinta que coordinamos en 2020 los Profesores Ángel Viñas, Jesús Martínez y el que esto escribe para Marcial Pons, Luces sobre un pasado deformado.

Los libros sobre la Guerra Civil es una obra colectiva de varios especialistas que se centra en un análisis sobre temáticas de indudable interés pues, como señalábamos Ángel Viñas y yo en la mencionada obra de 2017: "en estos últimos años, las polémicas, con ser intensas en todo lo relacionado con la Guerra Civil, han tendido a desplazarse hacia planos muy concretos", entre los que mencionábamos la mayoría de los aquí abordados central o tangencialmente como ¿por qué desembocó la República en una guerra civil?, ¿a quién le atañe más la responsabilidad de la misma?, ¿por qué el desenlace de la misma?, ¿cuáles son el papel y la significación de la Guerra Civil en la Europa de los años treinta? Junto a la represión, sus mecanismos y sus resultados y cómo abordar el tema de la guerra civil en la España democrática y qué papel desempeña la polemizada «recuperación de la memoria histórica».

La presente obra, ahora con una segunda edición, tiene más interés al comprobar cómo en el caso español ha vuelto a resurgir en los últimos años un combate por esa memoria histórica, cuando no por la historia misma, muy particularmente respecto a la Guerra Civil y también a su consecuencia: el Franquismo. En este contexto sirve incidir, como se deduce también de esta obra que, cualesquiera que sean las valoraciones que se hagan sobre

1. Bibliografías de la Guerra Civil Española, Madrid, Marcial Pons, 2017. 
la experiencia republicana hay una cosa que entiendo es clara: la conspiración militar para derribar a los gobiernos tras las elecciones del Frente Popular se inició inmediatamente y se desarrolló apoyándose en argumentos falsos, entre ellos al amparo de un imaginado proceso de «sovietización» alentado por la Komintern y el Partido Comunista con el fin de hacer de España un remedo de República popular como las existentes tras la Segunda Guerra Mundial, o atribuyendo las últimas responsabilidades del golpe en marcha a una supuesta radicalización del Partido Socialista y a un presunto revolucionarismo de la izquierda en general, ignorando al tiempo lo que estaban haciendo las derechas, de lo que es un ejemplo las gestiones con Mussolini en la primavera del 36.

La responsabilidad del golpe está bien tratada en el primero de los capítulos del presente libro del que es autor Eduardo González Calleja. En su contribución en la mencionada Luces sobre un pasado deformado con el expresivo título de "La República, ¿víctima o responsable de la Guerra Civil”, analizando las causas del golpe de Estado de julio, Eduardo González Calleja desentraña la dinámica de varios tópicos justificativos del mismo: desde el mito de la revolución social inminente, el tópico del deterioro del orden público, la incidencia en el rearme paramilitar de la izquierda al tiempo de la deriva violenta de la derecha, o el tópico del golpe de Estado preventivo para justificar una conspiración en marcha desde hacía tiempo ${ }^{2}$. En esta misma línea, en este capítulo se analiza la dinámica de las diferentes interpretaciones del golpe de Estado de julio que se van modulando según vayan cambiando las circunstancias internas y externas de la dictadura y los avances en la historiografía, incidiendo especialmente en los cambios producidos desde la última etapa del Franquismo y la Transición con peso creciente de los historiadores desde el inicio de ésta. Analiza asimismo con acierto las polémicas en torno a la historia y la memoria de la Guerra Civil, que como señala justamente, arrastra consigo la de la República, marcando las limitaciones y trampas de una visión revisionista de la historiografía y la pseudohistogriografía sobre la guerra, definida en su versión más tajante por la defensa de la tesis de que "no fue la guerra la que destruyó la democracia, sino que la destrucción de la democracia la que trajo la guerra”. Refleja bien la actitud cambiante de la derecha que accede al poder a mediados de los noventa sobre la memoria del 18 de julio, desde una posición de cautela en principio a la oposición a la Ley de la Memoria Histórica, posición en la que sigue respecto a la Ley de Memoria Democrática ahora en trámite. Pero entiende que serán los años de discusión y aprobación de la Ley de 2007 cuando se produzca el paso de la evocación memorial al predominio de la reflexión académica, considerando a Aróstegui como impulsor fundamental. La explicación del proceso que desemboca en el golpe obtendría también luz de los trabajos de Rafael Cruz de 2006, que atribuye claramente el golpe a las iniciativas de los militares dando lugar al derrumbe del Estado y el inicio de la guerra, y de Francisco Alia Miranda de 2011, que diseccióna con precisión la conjura, que sería una sola y meticulosamente preparada aunque se fuera gestando en diversas etapas.

2. En J.A. Blanco, J.A. Martínez y A. Viñas (eds.), Luces sobre un pasado deformado. La Guerra Civil ochenta años después, Madrid, Marcial Pons, 2020. 
Y aborda también, prescindiendo del pseudorevisionismo paleo-, neo- o posfranquista, el revisionismo procedente del ámbito universitario, respetable y debatible, aunque señale que en ocasiones sus posiciones parezcan inquietantemente próximas a las de ciertos "propagandistas" en la denigración del sistema republicano y la atribución de responsabilidades respecto a la guerra.

Para finalizar con la afirmación de que respecto al golpe de julio, de honda presencia en la memoria colectiva de los españoles, más allá de su mitificación por el franquismo, los especialistas coinciden en caracterizarlo como un golpe militar que derivó en guerra civil que terminó en un proceso contrarrevolucionario que acabó persiguiendo la liquidación del experimento democrático que supuso la Segunda República.

Matilde Eiroa aporta un análisis muy actualizado de las principales obras, pero también de las principales cuestiones, del panorama complejo de la implicación internacional en el conflicto español. Señala las cuestiones en las que va habiendo acuerdo y aquellas sobre las que siguen existiendo importantes discrepancias historiográficas como el origen de la intervención, las causas, la dimensión y sus efectos en el resultado final de la guerra. Así como señala también los campos insuficientemente tratados y las ausencias documentales.

Como es inevitable, desde la redacción de este capítulo se ha seguido progresando en algunos campos y están en marcha nuevas investigaciones. En la obra de Marcial Pons de 2020 se avanza en la valoración de los apoyos en un trabajo de Miguel I. Campos, más contundente al señalar la persistencia de algunas falsedades de la historiografía franquista y neofranquista que llegan hasta la actualidad, o en la valoración del abandono de la República por las democracias, como fundamenta David Jorge. La implicación internacional por la vía de los servicios secretos y las actuaciones diplomáticas también se ve mejor en el estudio de Carlos Piriz sobre la Quinta Columna y sus relaciones con las legaciones extranjeras. La intervención soviética sin duda se verá más esclarecida con la próxima obra de Ángel Viñas asentada sobre fuentes documentales soviéticas.

Las dimensiones militares es un capítulo imprescindible al plantearse el por qué el golpe de estado de julio se transformó en guerra civil y el desenlace de la misma. Abordar el tema desde la perspectiva militar es imprescindible pues, aunque cualquier guerra civil debería analizarse desde diversas perspectivas, no se puede olvidar que ese conflicto es preferentemente un enfrentamiento militar. La guerra de 1936 fue principalmente un conflicto bélico cuyo desenlace en último término se produjo militarmente. Y se inició precisamente por una conspiración militar. Francisco Alía Miranda y Fernando del Puell, entre otros, han aclarado el papel conspirador que tuvo un grupo de militares con distintas posiciones ideológicas, desde mucho antes de que, como algún autor vuelve a argumentar, el asesinato de Calvo Sotelo representara el punto de no retorno.

El análisis que Arturo García hace en esta obra tiene muy presente que hay una amplia distancia entre los escritos de José Martínez Bande sobre el Ejército de los franquistas o de Ramón Salas Larrazábal o Alpert sobre el republicano y la literatura militar actual, observando la influencia determinante que ha tenido la nueva historia militar. Así, es muy útil el recorrido que se hace por las diversas etapas de la historiografía de tipo militar, tratando pormenorizadamente las publicaciones más significativas. La limitación de espacio seguramente 
es la causa de que la referencia a muchas de las obras sea meramente nominativa, sin apenas valoración, y algunas como las de Jesús Salas Larrazábal las necesitan, como ha demostrado Ángel Viñas. Pero en conjunto este capítulo aborda los avances más significativos en el conocimiento de los aspectos militares de la guerra civil, con incidencia en aspectos como el reclutamiento y la moral de la tropa. Quizás convendría incidir asimismo, como hace Puell de la Villa en la mencionada obra en Marcial Pons de 2017 en la significación de los estudios sobre contrainteligencia o las deficiencias más notables que existen aún en cuanto a logística, junto a estudios globales sobre el Ejército franquista, aspecto que el autor sí señala.

En el capítulo que escribe Francisco Sánchez Pérez sobre voluntariado y milicias se resalta lo poco que se ha avanzado en el conocimiento de éstas en las dos últimas décadas, aunque se señala la significación de algunos trabajos recientes.

Considero que este capítulo era especialmente necesario. Señala con acierto las limitaciones de los estudios sobre milicias publicados antes de los ochenta, procedentes casi exclusivamente de historiadores militares y militantes políticos, e incide en el impulso de renovación que ejemplifica Aróstegui en esa década que, sin embargo, se muestra al empezar el nuevo siglo claramente inacabado cuando se acometen nuevas formas de acercamientos menos centradas en lo cuantitativo. En conjunto el capítulo refleja bien las líneas de avance y las limitaciones de las mismas hasta el momento de la mano de la incidencia en el memorialismo y las aportaciones de la historia local, así como la atención a la contribución femenina, con trabajos significativos de Ana Martínez Rus o Encarnación Barranquero.

Se señala que dentro de la nueva historia militar se ha prestado atención, insuficiente, a la interacción de la sociedad, la cultura y las fuerzas armadas, ponderando las reales implicaciones de los combatientes y las limitaciones de la movilización voluntaria y de la participación de la tropa en general, o las motivaciones de su incorporación (aunque en este aspecto se ha avanzado de la mano de la literatura). Nos faltan estudios comparativos y un análisis sociodemográfico de las milicias, que se conoce para algunas unidades y para algunas zonas. Conocemos relativamente bien las carlistas, pero mucho menos las falangistas. Y en el bando republicano relativamente bien las comunistas pero no las socialistas, ni las del POUM o las anarquistas, a pesar de algunos nuevos estudios sobre éstas. Se ha avanzado en algunas cuestiones de la mano de la publicación de los testimonios de los propios milicianos/as, con aportaciones significativas sobre el compromiso ideológico, la violencia y la represión, la derrota y sus implicaciones o el papel jugado por las mujeres.

Como manifestación de violencia, la Guerra Civil afectó a todos los sectores y a la mayor parte del territorio directa o indirectamente. Se vio acompañada de un fenómeno corriente en tales casos, pero llevado a cabo con singular empeño, aunque no con los mismos resultados y bajo las mismas categorías: la represión. Gracias, en parte, al movimiento por la recuperación de la memoria histórica, al fenómeno del descubrimiento de incontables «fosas del olvido» y a los buenos resultados que la historia local ha dado en este terreno, el estudio de las actividades represivas de ambos contendientes se ha convertido hoy en uno de los capítulos más relevantes de la historiografía española. En el libro que comentamos se dedica especial atención a examinar la historiografía que se ha ocupado del fenómeno represivo. Teniendo en cuenta que la complejidad del tema exige conjugar perspectivas múltiples y 
se ha abordado en distintas aproximaciones historiográficas muy numerosas en los últimos tiempos. Sería risible pensar que un fenómeno tan complejo pudiera abordarse de forma simplista, como a veces se ha hecho.

No es el caso en esta obra y Javier Cervera tiene muy en cuenta la necesidad de enmarcar la represión en el marco conceptual, la violencia política, y ámbitos territoriales muy diversos, las distintas retaguardias, y no solo distinguidas por bandos. Incide en matizar la determinación de violencia legalizada o represión política, la relación de estas con el concepto de orden público, una vez que la sublevación se convierte en guerra civil con dos bandos que pretenden aplicar sus propios conceptos de orden público (señalando, de paso, los pocos estudios sobre la actuación de las fuerzas de orden público durante la guerra). Señala el hecho de que se han identificado en ocasiones como violencia política actos que solo lo son, o lo son en parte de violencia doméstica, particular y se hace una pregunta fundamental: por qué la sublevación dio lugar a un intensísimo proceso de violencia y represión, que acertadamente contesta remitiéndose a las tesis expuestas por Julio Aróstegui, a quién también acertadamente le reconoce su contribución al análisis de la violencia política en la España del XX.

Autor de varias obras sobre violencia política y represión, Javier Cervera analiza con atino la historiografía sobre esta temática producida desde el momento del conflicto, poniendo el acento en el impulso que tiene desde la Transición, la contribución de la historia local y la incidencia desde mediados de los noventa en la memoria histórica, sin olvidar los avances que se van produciendo no solo con el paso de los análisis especialmente cuantitativos a la consideración de la represión como un fenómeno complejo que no se limita a la eliminación, prisión o depuración del considerado como enemigo. Sin duda supone una útil guía en este campo de la violencia política y la represión del que sigue vigente una continua edición de nuevos trabajos.

Manuela Aroca Mohedano justifica el objeto de su estudio en que, en un conflicto profundamente ideologizado que se acaba convirtiendo en guerra total en la que se busca implicar a toda la sociedad en ambos bandos, la cultura, la propaganda y la prensa constituyen los cauces fundamentales de la formación de las posiciones ideológicas.

Incide acertadamente en el impulso que han recibido estos estudios a partir de los debates sobre la memoria de la guerra y también de la historia local. Señala asimismo el que en ciertos campos de la cultura los análisis han venido de la mano de especialistas en disciplinas no historiográficas, y no tanto desde la historia, lo que ha ocurrido menos respecto a la prensa y la propaganda.

Constata que los análisis de los últimos años se han centrado en el bando sublevado, lo que sirve para equilibrar la tendencia anterior, en especial respecto a prensa y propaganda. Como señala también la cuestionable calidad de muchas de las creaciones culturales en el contexto de las urgencias de la guerra. En conjunto se analizan con tino las obras fundamentales.

A la prensa y la propaganda se le ha prestado especial atención ya desde los años ochenta, primero a la generada en el bando republicano, tendiendo a equilibrar la situación desde mediados de los noventa, no ignorando un dato significativo como es la colaboración propagandística entre franquismo y salazarismo. También se resalta lo que supone la guerra 
española como momento de expansión de la utilización de la propaganda como medio de incidencia y control social.

La importancia de la propaganda en la guerra española reside, como refleja Jesús Martínez en el libro de Marcial Pons de 2020, en que antes de la misma no había dos bandos político -ideológicos irreconciliables abocados a un enfrentamiento irreversible y fue precisamente la propaganda durante y después de la misma la que configuró esos márgenes explicativos de la guerra y de la propia República, contaminando desde ahí todo por la teoría de los bloques irreconciliables. La propaganda debía conformar esos bloques, ganando a los combatientes, pero también a la población de la retaguardia y a la opinión pública internacional. De ahí su importancia. La propaganda buscaba la movilización y las aplicaciones no fueron lo mismo en el bando republicano, en el que en principio se había dinamitado el Estado, aflorando diferencias que se mantienen de alguna manera durante toda la guerra, que en el sublevado, con una estricta militarización de la propaganda

La autora señala la atención historiográfica a la propaganda en el bando sublevado, intensa en los últimos años y la ausencia de estudios suficientes similares en el bando republicano, marcando las aportaciones más relevantes, reflejando asimismo la persistente atención a los corresponsales de guerra.

Rosario Ruiz Franco presenta en su trabajo la evolución de la producción historiográfica sobre las mujeres en la guerra, reflejando el olvido del tema hasta los años setenta y las modificaciones que se han ido produciendo desde entonces a la luz de los cambios en la historiografía de la guerra y la incorporación a la misma de la perspectiva de la historia de las mujeres y del género, orientación que ha posibilitado avanzar en el conocimiento general sobre el conflicto español de los años treinta. El olvido del tema lo refleja el hecho de constatar que en los análisis de la historiografía de la guerra, incluso los aparecidos en el presente siglo, de algunos de los cuales soy autor, se obviaba o meramente se mencionaba de paso.

Analiza los estudios que se centran en el análisis de las culturas políticas republicanas, incidiendo en la relación entre ciudadanía, mujeres e identidades de género, aunque centra propiamente el foco en la actuación y situación femeninas en la guerra. Aborda también desde esas perspectivas de género el exilio, la resistencia antifascista y la represión, aportando un enriquecimiento del conocimiento sobre estos campos. Señala la significación de la utilización de fuentes orales y el papel de memorias y biografías.

En cuanto a las nuevas líneas de investigación, señala con acierto el impulso que han recibido estos estudios en lo que va de siglo de la mano del interés por la memoria histórica o la represión como fenómeno complejo, dentro del cual se analiza la depuración como una forma de control y represión sobre las mujeres, la denominada línea de "represión sexuada" que responde a razones ideológicas, pero también de género. Particular atención se ha prestado a la presencia de las mujeres en las cárceles, analizando tanto la represión sufrida como las muestras de resistencia. También las distintas formas de represión sufrida por las mujeres en la retaguardia, que tiene algunas características y manifestaciones específicas.

El exilio ha recibido un intenso tratamiento, aunque todavía incompleto. De la mano de estudios específicos y de biografías y memorias se ha puesto el acento en la mujer miliciana, su significación y simbología, aunque faltan estudios sobre su real eficacia militar y el 
proceso de su reconversión hacia la retaguardia. Se señala con acierto que, en líneas generales, se ha prestado más atención a la mujer republicana que a la del bando franquista, aunque se comenta el incremento de trabajos en esta dirección, especialmente sobre la Sección Femenina, pero también respecto a las republicanas en la guerra quedan campos en los que profundizar. No se olvida de mencionar la operatividad de nuevas fuentes y particularmente las icónicas y orales crecientemente utilizadas.

Y han seguido apareciendo obras tras el cierre de la edición de este libro, como se pone de manifiesto en un trabajo de Encarnación Barranquero ("Lo que hemos aprendido sobre el papel de las mujeres en la Guerra Civil y la posguerra. Datos y reflexiones de un balance") que deberá publicarse en la segunda edición de la mencionada Luces sobre un pasado deformado.

El último capítulo sobre "El final de la guerra y el golpe de Estado del coronel Casado" es sumamente ilustrativo. Ángel Bahamonde es un reputado especialista en esta cuestión con una obra notable en colaboración con Javier Cervera a finales del pasado siglo, reeditada, y una reciente sobre el propio golpe de Casado. Bahamonde analiza con precisión el tratamiento historiográfico del final de la guerra diseccionando las aportaciones más relevantes en cada etapa, como queda de manifiesto al abordar los trabajos de Luis Romero, y analizando las aportaciones de los personajes concernidos, especialmente en el campo republicano, sus visiones autojustificativas en muchos casos y sus efectos. Especialmente útil me parece la identificación de las fuentes documentales más fructíferas para los estudios de los últimos veinte años, de las que hace un ajustado análisis con incidencia en la valoración de dos personajes claves como son Casado y Besteiro.

Algunos aspectos tendrán matices como se desprende de trabajos realizados después de publicado este artículo y el esperado tratamiento de algunos otros fondos. Así, Paul Preston, en el mencionado libro de Marcial Pons de 2020 critica inmisericordemente a Casado y la crítica, de otra forma, se extiende a Besteiro. La tesis de Carlos Piriz, "En campo enemigo: la Quinta Columna en la Guerra Civil Española 1936-1939)” aporta muchas claves sobre el papel de esos grupos y la actuación de los personajes señalados. Como hemos mencionado, Angel Viñas tiene en preparación un nuevo libro sobre la actuación de la URSS en la Guerra Civil con la utilización, entre otros, de nuevos fondos soviéticos.

En resumen, los autores de esta obra aportan una buena y útil visión de los resultados más significativos de la historiografía académica, especialmente la reciente, sobre ciertos elementos centrales del conflicto español de los años treinta del siglo pasado, contribuyendo, con otras ya citadas, a superar muchos mitos y llenar algunas lagunas en el conocimiento de la guerra civil española, suscitando a la vez a nuevos interrogantes 